\title{
Tumor-Targeted Drug Delivery as a Successful Approach for Reducing Doxorubicin-Induced Cardiotoxicity
}

\section{Nasibeh Mohammad Ali Pourradi}

Tabriz University of Medical Sciences

Yadollah Azarmi ( $\sim$ azarmiy@tbzmed.ac.ir)

Tabriz University of Medical Sciences

Hossien Babaei

Tabriz University of Medical Sciences

Behzad Baradaran

Tabriz University of Medical Sciences

Behrooz Shokouhi-Gogani

Tabriz University of Medical Sciences

\section{Zahra Abbasnejad}

Tabriz University of Medical Sciences

Hamed Hamishehkar

Tabriz University of Medical Sciences

\section{Research Article}

Keywords: Doxorubicin, Cardiotoxicity, Breast cancer model, Tumor-targeted drug delivery, Folate targeting, Nanoparticles

Posted Date: November 30th, 2021

DOI: https://doi.org/10.21203/rs.3.rs-960651/v1

License: (9) (i) This work is licensed under a Creative Commons Attribution 4.0 International License. Read Full License 


\section{Abstract}

Doxorubicin (DOX) is an effective chemotherapy drug used to treat many malignancies, including breast cancer. However, its clinical application is severely limited by cardiotoxicity. This study investigated if using thermo/pHsensitive magnetic nanoparticles decorated with folate (folate-poly-MNPs) as tumortargeted drug delivery systems (DDSs) could reduce the cardiotoxicity and inflammatory properties of DOX in a rat model of breast cancer. In this study, forty rats were intravenously administered the control, DOX, DOX-poly-MNPs, and DOXfolate-poly-MNPs every 48 hours for 12 days. The cardiac health monitoring following breast cancer therapy confirmed that the novel smart DDS improved ECG pattern, left ventricular function, blood pressure parameters, and heart weight index. Moreover, it could decrease myocardial cell death by decreasing the protein levels of BAX, c-PARP1, and c-caspase-3, with concomitant downregulation of the BAX/Bcl-2 ratio, compared to the commercial DOX. In addition, the DOXfolate-poly-MNPs treatment significantly reduced NLRP3 inflammasome activation in cardiomyocytes, which was mediated by caspase-1 inhibition, and suppressed upregulation of IL-1 $\beta$ and IL18 protein expression to prevent myocardial damage. In this regard, the developed folatepolyMNPs could be represented as a new potential drug delivery system for breast cancer chemotherapy due to the combination of passive and active targeting aimed at preventing nonspecific body distribution, inhibiting NLRP3 inflammasome activation, and consequently reducing DOX cardiotoxicity as its main adverse effect.

\section{Introduction}

Cardiovascular toxicity is a major side effect of Doxorubicin (DOX), one of the most commonly used antineoplastic agents to treat several types of cancer, including solid tumors, ovarian, and breast cancer (Khan et al., 2014, Shabalala et al., 2017, Cappetta et al., 2018, Songbo et al., 2019). Despite the widespread use of DOX due to its wellestablished dosedependent cardiotoxicity, its use in cancer treatment is limited (Burridge et al., 2016, McGowan et al., 2017). DOXinduced cardiotoxicity (DIC) ranges from asymptomatic subclinical abnormalities such as reversible hypotension, pericarditis, transient electrocardiographic changes, and left ventricular systolic dysfunction (LVSD) to lifethreatening completions such as congestive heart failure (CHF) or irreversible cardiomyopathy (Razmaraii et al., 2016a). Therefore, several cancertargeting agents have been suggested as a potential approach to improve efficiency and reduce the side effects of peripheral toxicity drugs such as DOX (Park, 2002, Schiffelers et al., 2003, Vicent and Duncan, 2006, Payne and Raghavan, 2007, Tacar et al., 2013, Khan et al., 2014).

As a result of improved pharmacokinetics and bio-distribution, Drug Delivery Systems (DDSs) have shown remarkable efficacy in chemotherapy by combining passive and active targeting on a single platform to enhance permeability and retention effect (EPR), while also increasing the accumulation of nanoparticles (NPs) by diffusion into the leaky tumor vasculature, referred to as passive drug targeting (Greish, 2010). A further approach to achieving high selectivity is the active targeting method. For example, folate, a non-immunogenic ligand, has a high affinity for folate receptor-a (FOLR1), present on 
the surface of a broad spectrum of tumors, facilitating the cellular uptake of folate-nanocarriers by receptor-mediated endocytosis (Hartmann et al., 2007, He et al., 2021).

Moreover, $\mathrm{pH}$-responsive delivery carriers were developed for $\mathrm{pH}$-triggered controlled drug release, aiming at increasing more selective use of $\mathrm{pH}$ values, which differ significantly in various tissues and cellular compartments. These delivery systems are sensitive to a single $\mathrm{pH}$ level, i.e., the tumor microenvironment is more acidic $(\mathrm{pH} 6.5)$, resulting in increased retention of NPs than normal cells ( $\mathrm{pH} \mathrm{7.4).} \mathrm{However,} \mathrm{both}$ endosomes and lysosomes have an even lower $\mathrm{pH}$ value (5.0-5.5). Therefore, the extracellular or intracellular pH level influences the effectiveness of DDSs through the EPR effect, such as polymer-drugnanocarriers, likely to increase drug accumulation, control drug delivery, and promote cellular internalization at the tumor site (Yu et al., 2010, Bertrand et al., 2014). The rate of drug release increases with the temperature rise since tumor tissues have temperatures higher than physiological temperatures. Thus, the temperatureresponsive polymer (PIPAAm) plays a crucial role in targeted DDSs for cancer cells (Lanzalaco and Armelin, 2017, Oroojalian et al., 2018).

NLRP3 inflammasome is composed of a large protein complex of NLRP3 (nucleotide-binding oligomerization domain (NOD)-like receptor (NLR) protein 3), ASC (apoptosis-associated speck-like protein containing a caspase recruitment domain), and pro-caspase-1. Recent studies have demonstrated that DOX chemotherapy induces pyroptosis in cardiomyocytes via the NLRP3-Inflammasome-Caspase-1 Pathway, an inflammatory caspases-dependent programmed cell death by increasing the production of pro-inflammatory cytokines including IL-1 $\beta$ and IL 18, consequently forming plasma membrane pores, inflammation responses, cardiomyocyte death, and cardiac damage (Meng et al., 2019, Zeng et al., 2020, Liu et al., 2021).

In the previous study, the targeted drug delivery of DOX decorated with poly ( $\mathrm{N}$ isopropyl acrylamide-coitaconic acid) and conjugated with or without folic acid was introduced as a novel dual-responsive magnetic nanocarrier. The efficacy and cytotoxic effects of novel nanocarriers were evaluated thoroughly in vitro study and their successful outcomes were confirmed (Ghorbani et al., 2016). Therefore, it is important to develop new strategies for targeted drug delivery of DOX to inhibit the inflammatory responses mediated by the NLRP3 inflammasome and reduce DOXinduced cardiotoxicity in the rat model of breast cancer, as illustrated in Fig. 1. The present study decided to design this study to investigate whether there is a significant correlation between increasing DOX delivery at the tumor site and decreasing DOX cardiotoxicity using novel dualresponsive magnetic nanocarriers. Such findings may open up a new horizon in effective DOX chemotherapy, which will be a significant step forward for patients with lower cardiotoxicity and higher survival rates in the future.

\section{Materials And Methods}

\section{Materials}


The materials used included: 7, 12-dimethylbenz [a] anthracene (DMBA) and RIPA buffer (Sigma Aldrich Co. LLC), Doxorubicin hydrochloride (Sicor Company, Rho, Italy), Xylazine and Ketamine hydrochloride (Alfasan, the Netherlands), one-step RT-PCR kit (BioFact, Daejeon, South Korea), Polyvinylidene Difluoride (PVDF) membrane (Roche, Germany), TUNEL Apoptosis assay kit (Elascience, Wuhan, China), BAX antibody (sc-7480), Bcl-2 antibody (sc-492), caspase-3 antibody (sc-7148), PARP1 antibody (sc-8007), ASC antibody (sc514414), caspase-1 antibody (sc-392736), IL-1 $\beta$ antibody (sc-12742), IL-18 antibody (sc6179), $\beta$-actin Antibody (sc-47778), and goat anti-rabbit secondary antibody (sc2357) (Santa Cruz Biotechnology, Dallas, TX), enhanced chemiluminescence detection kit (Pierce, Rockford, IL), and RNX PLUS kit (Cinnagen, Iran). Besides, DOX-folate-conjugated poly (NIPAAm- co-IA) @Fe304 NPs and DOXpoly (NIPAAm- co-IA) @Fe304 NPs were provided by the Pharmaceutical Technology Laboratory, Drug Applied Research Center, Tabriz, Iran (Ghorbani et al., 2016).

\section{Animals}

Female Sprague-Dawley rats ( $n=40,120 \pm 5 \mathrm{~g}, 35$ days old) were purchased from the Razi Vaccine and Serum Research Institute, Iran. In the experimental room, three animals were housed in standard polycarbonate cages at room temperature $\left(25 \pm 2^{\circ} \mathrm{C}\right)$ with $55 \pm 5 \%$ relative humidity and a $12: 12$ hour lightdark cycle. Rats were supplied with water and a normal chow diet ad libitum. Study procedures were approved by the Institutional Animal Ethics Committee at Tabriz University of Medical Sciences (IR.TBZMED.REC.1396.492).

\section{Tumor Induction Protocols}

Mammary tumorigenesis was induced through a subcutaneous injection of DMBA ( $25 \mathrm{mg} / \mathrm{rat})$ in sesame oil in 47-day-old female Sprague-Dawley rats. At 8 weeks post-DMBA, the rats were palpated twice a week to detect the presence and location of mammalian tumors. The experiment started when the volume reached $1000 \mathrm{~mm}^{3}$ (Rajendran et al., 2019).

\section{Experimental design}

Forty mammary tumor-bearing animals were divided into four groups, 10 animals in each group, and administered intravenously (i.v.) for 12 days according to the following experimental procedure (Razmaraii et al., 2016c):

Group-I rats received saline,

Group-II rats were treated with DOX hydrochloride $(2 \mathrm{mg} / \mathrm{kg} / 48 \mathrm{~h})$,

Group-III rats were treated with DOX-poly (NIPAAm- co-IA) @Fe304 NPs (2 mg/kg/48 h),

Group-IV rats were treated with DOX-folate-conjugated poly (NIPAAm- co-IA) @Fe304 NPs (2 mg/kg/48 h). All mammary tumor-bearing rats were observed daily and weighed every other day to assess possible toxicity. 


\section{Recording of the electrocardiogram and hemodynamic parameters}

48 hours after the last injection, animals were anesthetized intraperitoneally with a standard dose of ketamine and xylazine. To prevent blood clots, rats also received Heparin $2000 \mathrm{U} / \mathrm{kg} / \mathrm{SC}$. The electrocardiogram (ECG) was recorded using three subcutaneous electrodes by inserting Leadll into both hind-paws and the right forepaw of each rat. The sensors were attached to the bioamplifier to amplify and filter the raw data before transmitting it to the Powerlab data acquisition system (ADI Instruments, Australia). Therefore, the RR interval, QT interval, etc., were measured based on the ECG and the recording lasted for 10 min (Razmaraii et al., 2016b).

\section{Left ventricular function analysis}

After the right carotid artery was isolated from the vagal nerve, an oblique cut was made on the ventral surface of the artery with micro-scissors. For the assessment of systolic arterial pressure (SAP), diastolic arterial pressure (DAP), and mean arterial pressure (MAP), a Millar pressure catheter (SPR-407, Millar Instruments; Houston, TX) was inserted into the right carotid artery. Then it was gently advanced to the left ventricular for hemodynamic data collection, including heart rate, the maximal left ventricular systolic pressure, the minimum and maximum rate of increase in left ventricular pressure (mindP/dt, maxdP/dt), contractility index, enddiastolic pressure (EDP), etc. Lab Chart7 software (ADInstruments; Australia) was used for data acquisition and analysis (Razmaraii et al., 2016a).

\section{Heart weight index $(\mathrm{HWl})$}

At the end of the study, the heart of the animal was excised and weighed; the heart weight index was computed by dividing the heart weight to final body weight (Razmaraii et al., 2016c).

\section{Histopathological examination}

The ventricular tissues were divided into two parts; one part was snap-frozen and preserved $a t 70^{\circ} \mathrm{C}$ for biochemical examination. The other part was fixed with $10 \%$ buffered formalin (v/v), embedded in a paraffin wax block, and tissue processed. The standard hematoxylin and eosin staining (H\&E) were used for histopathological examinations. A pathologist scored the H\&E-stained slides from zero to three to evaluate the severity scores of cardiomyopathy (CMY) and morphological characteristic changes of the myocardium as follows: interstitial edema, inflammatory cells, myocardial fiber swelling, vacuolization, myocytolysis, necrosis (Saad et al., 2004, Razmaraii et al., 2016b).

\section{Evaluation Of Dox-cardiotoxicity}

\section{TUNEL staining}


DNA fragmentation, DNA double-strand breaks (DSBs), and apoptotic cells in the cardiac tissues were evaluated by TUNEL staining following the manufacturer's instructions. The binding of digoxigeninconjugated dUTP to catalyze terminal deoxynucleotidyl transferase was used to detect DSBs in apoptotic cells. After binding of streptavidin-labeled horseradish peroxidase, the apoptotic cells were labeled with $D A B$, which could be observed by light microscopy. The paraffin-embedded tissue sections were deparaffinized and rehydrated. Then, the slides were deproteinized using $100 \mu \mathrm{L}$ proteinase $\mathrm{K}$ for $15 \mathrm{~min}$. Next, the slides were incubated with $10 \mu \mathrm{L}$ terminal deoxynucleotidyl transferase buffer (TdT) for $60 \mathrm{~min}$, $10 \mu \mathrm{L}$ HRP anti-fluorescein antibody for $30 \mathrm{~min}, 10 \mu \mathrm{L}$ DAB solution for $10 \mathrm{~min}$, and finally hematoxylin solution for $1 \mathrm{~min}$ at $37^{\circ} \mathrm{C}$. All slides were dehydrated and mounted by routine procedures (Raa et al., 2007).

\section{Gene expression analysis}

The RNX PLUS kit was used to isolate total RNA, as instructed by the manufacturer. The concentration and quality of RNA were determined by the $260 / 280$ ratio using a NanoDrop ${ }^{\text {TM }} 2000 / 2000$ c Spectrophotometers (Thermo Fisher Scientific Inc, Wilmington, DE). The cDNA was synthesized by BioFact $^{\text {tM }}$ OneStep RT-PCR kit, Korea. Relative mRNA levels of BAX, Bcl2, PARP1, caspase 3 , and $\beta$-actin genes were assessed using the detector system (Applied Biosystems, Foster City, CA). The sequences of oligonucleotide primers are shown in Table 1. The real-time PCR assay was performed by the following PCR protocol in triplicate: initial denaturation, $95^{\circ} \mathrm{C}$ for $10 \mathrm{~min}$; 45 cyclic denaturation, $95^{\circ} \mathrm{C}$ for 10 secs; optimized annealing temperature, $55^{\circ} \mathrm{C}$ for 30 secs; $72^{\circ} \mathrm{C}$ for $1.20 \mathrm{~min}$ for the extension. At each step, the PCR products were monitored by measuring the increased fluorescence intensity of SYBR green bound to double-stranded DNA. The thermal melt curves were generated after the last extension step in the range of $60^{\circ} \mathrm{C}$ to $99^{\circ} \mathrm{C}$. Finally, the amplification efficiency of target and reference genes was evaluated using the 2- $\Delta \Delta \mathrm{CT}$ calculation method for calculating relative quantities (Latifi et al., 2018).

Table 1

Sequences of primers applied for quantitative RT-PCR.

\begin{tabular}{|c|c|c|c|}
\hline Target & Forward Primer & Reverse Primer & Size (bp) \\
\hline BAX & 5'-AGCTGCAGAGGATGATTGCT-3' & $\begin{array}{l}\text { 5'-AGCAAAGTAGAAAAGGGCAACC- } \\
3^{\prime}\end{array}$ & 128 \\
\hline $\mathrm{Bcl}-2$ & 5'-TCGCGACTTTGCAGAGATGT-3' & 5'-GAAGAGTTCCTCCACCACCG-3' & 88 \\
\hline $\begin{array}{l}\text { Caspase- } \\
3\end{array}$ & $\begin{array}{l}\text { 5'-TGGAACTGACGATGATATGGCA- } \\
3^{\prime}\end{array}$ & 5'-CTGGATGAACCATGACCCGT-3' & 123 \\
\hline PARP1 & 5'-СССТCACCGAATCTCCTTAG-3' & 5'-СССААСТTТСССТСТАСТGС-3' & 125 \\
\hline$\beta$-actin & 5'-CATCCTGCGTCTGGACCTGG-3' & 5'-TAATGTCACGCACGATTTCC-3' & 116 \\
\hline
\end{tabular}

\section{Western blot assays}


Western blot analysis was used to evaluate the expression of Bcl-2, BAX, caspase-3, PARP1, ASC, caspase-1, IL-1 $\beta, \mathrm{IL}-18$, and $\beta$-actin proteins in the ventricular tissue. Snap-frozen tissue was lysed in RIPA buffer and a protease inhibitor cocktail. The homogenate was centrifuged for $15 \mathrm{~min}$ at $14000 \times \mathrm{g}$. The protein content of the supernatant was measured using the NanoDrop 2000c (Thermo-scientific), and the protein mixing loading buffer was boiled in an electrophoresis gel for $5 \mathrm{~min}$. SDS-PAGE (10\% gels) was used to isolate the protein at $50 \mathrm{mg} /$ lane concentrations, and then blotted onto a polyvinylidene difluoride (PVDF) membrane.

All membranes were incubated at $4^{\circ} \mathrm{C}$ overnight with primary antibodies (anti-BAX (1:500), Bcl-2 (1:500), caspase-3 (1:500), PARP1 (1:500), caspase-1 antibody (1:1000), IL-1 $\beta$ antibody (1:1000), IL-18 antibody (1:500), and $\beta$-actin antibody (1:500) as an internal control). Next, the membranes were incubated under gentle agitation for 60 min with a secondary antibody (1:1000). Finally, the Enhanced Chemiluminescence (ECL) detection kit was used to visualize the protein bands on the membrane. The density of bands was quantified by Image $\mathrm{J}$ software; the relative density of protein bands was calculated for $\beta$-actin (Latifi et al., 2018).

\section{Statistical analysis}

Data are expressed as mean \pm SD. The difference between groups was analyzed by oneway ANOVA, followed by post hoc Dunnett's test and non-parametric Kruskal-Wallis multiple comparison tests, as needed. The data analysis was performed with GraphPad Prism 6.0 software (GraphPad Software, San Diego, CA). The $p$-value $<0.05$ was considered statistically significant.

\section{Results}

\section{Electrocardiographic recording}

The ECG tracings of the experimental groups are shown in Fig. 2. The ECG analysis of DOXtreated rats showed that the heart rate decreased significantly compared to the control group $(p<0.001)$.

In addition, the DOX group showed an increase in PR interval, RR interval, QRS complex, QTc interval, and QT interval compared to the control group $(p<0.001)$. However, the DOX loaded into tumor-targeted DDSs showed a significant improvement in ECG parameters compared to the DOX group, including heart rate, RR interval, PR interval, QRS complex, QTc interval, and QT interval, as shown in Table 2. 
Table 2

Electrocardiogram parameters in the study groups.

\begin{tabular}{|c|c|c|c|c|}
\hline \multirow[t]{2}{*}{ Parameter } & \multicolumn{4}{|l|}{ Group } \\
\hline & Control & DOX & DOXP-MNPs & DOX-FA-P-MNPs \\
\hline \multirow{2}{*}{$\begin{array}{l}\text { HR (BPM) } \\
\text { PRI (S) }\end{array}$} & $252.6 \pm 16.1$ & $213.5 \pm 22.1^{\star \star \star}$ & $242.4 \pm 14.6^{\# \#}$ & $245.0 \pm 12.9^{\# \# \#}$ \\
\hline & $0.032 \pm 0.002$ & $0.038 \pm 0.004^{\star \star \star}$ & $0.033 \pm 0.003^{\# \#}$ & $0.032 \pm 0.003^{\# \# \#}$ \\
\hline \multirow{2}{*}{$\begin{array}{l}\text { RRI (S) } \\
\text { QRS (S) }\end{array}$} & $0.240 \pm 0.013$ & $0.277 \pm 0.027^{\star \star \star}$ & $0.253 \pm 0.019^{\#}$ & $0.247 \pm 0.014^{\# \#}$ \\
\hline & $0.0371 \pm 0.001$ & $0.0418 \pm 0.001^{\star \star \star}$ & $0.0399 \pm 0.004$ & $0.0381 \pm 0.001^{\# \#}$ \\
\hline \multirow[t]{2}{*}{ QTI (S) } & $0.135 \pm 0.015$ & $0.164 \pm 0.009^{\star \star \star}$ & $0.144 \pm 0.011^{\# \#}$ & $0.140 \pm 0.011^{\# \# \#}$ \\
\hline & $0.066 \pm 0.009$ & $0.088 \pm 0.015^{\star \star \star}$ & $0.072 \pm 0.011^{\#}$ & $0.069 \pm 0.010^{\# \#}$ \\
\hline \multicolumn{5}{|c|}{$\begin{array}{l}\text { The ECG parameters were analyzed in the experimental groups for heart rate (HR), PR interval (PRI), } \\
\text { RR interval (RRI), QRS complex (QRS), corrected QT interval (QTC), and QT interval (QTI). Data are } \\
\text { expressed as mean } \pm \text { SD }(n=10) ;{ }^{\star \star \star} p<0.001 \text { vs. control group; }{ }^{\#} p<0.05, \# \#<0.01 \text {, and }{ }^{\# \# \# ~} p< \\
0.001 \text { vs. DOX group. }\end{array}$} \\
\hline
\end{tabular}

\section{Effects of DOX on hemodynamic functions}

Blood pressure and left ventricular functions were analyzed to assess hemodynamic function in the study groups, as indicated in Table 3. Systolic arterial pressure (SAP), diastolic arterial pressure (DAP), and mean arterial pressure (MAP) were significantly reduced in the DOX group compared to the control group $(p<0.001)$, whereas the DOXfolate-poly-MNPs group significantly improved SAP, DAP, and MAP compared to the DOX group ( $p<0.001)$. In the DOX-treated rats, left ventricular function showed a significant decrease in min pressure, max pressure, mean pressure, contractility index, $\min \mathrm{dP} / \mathrm{dt}$, and max $\mathrm{dP} / \mathrm{dt}$ compared to the control group $(\mathrm{p}<0.001)$. Furthermore, the EDP index of DOX group was dramatically enhanced compared to the control $(p<0.001)$. In contrast, the DOX treatment with tumortargeted DDSs significantly improved min pressure, max pressure, mean pressure, the EDP index, contractility index, min $\mathrm{dP} / \mathrm{dt}$, and max $\mathrm{dP} / \mathrm{dt}$ compared to the DOX $(\mathrm{p}<0.01)$. Furthermore, loading DOX into folate-poly-MNPs has a greater impact on decreasing DIC than loading DOX into polyMNPs. 
Table 3

Arterial and left ventricular functions in the study groups.

\begin{tabular}{|c|c|c|c|c|c|}
\hline \multirow[t]{2}{*}{ Parameter } & & \multicolumn{4}{|l|}{ Group } \\
\hline & & Control & DOX & $\begin{array}{l}\text { DOXP- } \\
\text { MNPs }\end{array}$ & $\begin{array}{l}\text { DOX-FA-P- } \\
\text { MNPS }\end{array}$ \\
\hline \multirow[t]{3}{*}{ Artery } & $\begin{array}{l}\text { Systolic pressure } \\
(\mathrm{mmHg})\end{array}$ & $\begin{array}{l}94.75 \pm \\
11.4\end{array}$ & $68.8 \pm 6.8^{\star \star \star}$ & $\begin{array}{l}85.3 \pm \\
10.7^{\# \#}\end{array}$ & $90.3 \pm 8.8^{\# \# \# ~}$ \\
\hline & $\begin{array}{l}\text { Diastolic pressure } \\
(\mathrm{mmHg})\end{array}$ & $76.3 \pm 14.2$ & $54.5 \pm 9.2^{\star \star \star}$ & $71.1 \pm 8.1^{\# \#}$ & $73.4 \pm 5.9^{\# \# \#}$ \\
\hline & $\begin{array}{l}\text { Means pressure } \\
(\mathrm{mmHg})\end{array}$ & $86.9 \pm 16.3$ & $60.6 \pm 7.6^{\star \star \star}$ & $79.6 \pm 8.9^{\# \#}$ & $85.1 \pm 7.5^{\# \# \#}$ \\
\hline \multirow[t]{7}{*}{$\begin{array}{l}\text { Left } \\
\text { ventricular }\end{array}$} & $\begin{array}{l}\text { Max pressure } \\
(\mathrm{mmHg})\end{array}$ & $96.4 \pm 4.9$ & $78.5 \pm 3.3^{* \star \star}$ & $\begin{array}{l}89.7 \pm \\
7.6^{\# \# \#}\end{array}$ & $94.0 \pm 7.5^{\# \# \#}$ \\
\hline & Min pressure $(\mathrm{mmHg})$ & $4.3 \pm 1.2$ & $2.4 \pm 0.7^{\star \star \star}$ & $3.5 \pm 0.7^{\#}$ & $3.9 \pm 0.8^{\# \#}$ \\
\hline & $\begin{array}{l}\text { Mean pressure } \\
(\mathrm{mmHg})\end{array}$ & $38.4 \pm 8.6$ & $27.0 \pm 3.6^{\star \star \star}$ & $33.4 \pm 3.0^{\#}$ & $35.8 \pm 2.3^{\# \#}$ \\
\hline & EDP index (mmHg) & $8.2 \pm 1.2$ & $\begin{array}{l}12.86 \pm \\
3.1^{\star \star \star}\end{array}$ & $10.1 \pm 1.8^{\#}$ & $9.3 \pm 1.9^{\# \#}$ \\
\hline & $\begin{array}{l}\text { Contractility } \\
\text { index }(1 / S)\end{array}$ & $88.1 \pm 13.7$ & $69.9 \pm 6.3^{\star \star \star}$ & $83.5 \pm 11.2$ & $84.9 \pm 8.8^{\# \#}$ \\
\hline & Max dP/dt (mmHg/S) & $\begin{array}{l}4444 \pm \\
761.6\end{array}$ & $\begin{array}{l}2971 \pm \\
319.1^{\star \star \star}\end{array}$ & $\begin{array}{l}3915 \pm \\
537.1^{\# \#}\end{array}$ & $\begin{array}{l}4196 \pm \\
489.5^{\# \# \#}\end{array}$ \\
\hline & Min $\mathrm{dP} / \mathrm{dt}(\mathrm{mmHg} / \mathrm{S})$ & $\begin{array}{l}-3311 \pm \\
786.9\end{array}$ & $\begin{array}{l}-2395 \pm \\
349.7^{\star \star \star}\end{array}$ & $\begin{array}{l}-3094 \pm \\
404^{\#}\end{array}$ & $\begin{array}{l}-3223 \pm \\
353^{\# \#}\end{array}$ \\
\hline
\end{tabular}

The arterial and left ventricular functions were analyzed in the study groups. Data are expressed as mean $\pm S D(n=10) ;{ }^{* *} p<0.001$ vs. control group; ${ }^{\#} p<0.05,{ }^{\# \#} p<0.01$, and ${ }^{\# \# \#} p<0.001$ vs. DOX group.

\section{Heart Weight Index (HWl)}

Rats treated with DOX, DOX-poly-MNPs, and DOX-folate-poly-MNPs groups experienced a significant decrease in final body weight compared to the control group $(p<0.001)$, whereas DOX-folate-poly-MNPs group showed a significant improvement in final body weight in comparison with the DOX group $(\mathrm{p}<$ 0.01 ; Table 4). The heart weight was significantly reduced in the DOX group compared to the control group ( $p<0.001)$. In contrast, the heart weight was increased in both tumor-targeted DDSs compared to the DOX group. The heart weight index (HWI) increased in all treatment groups compared to the control $(p$ $<0.001)$. However, despite an increase in the heart weight in the DOX-folate-poly-MNPs group, the HWI was significantly increased compared to the DOX group ( $<<0.01$; Table 4). 
Table 4

Heart weight index (HWI) in the study groups.

\begin{tabular}{|c|c|c|c|c|}
\hline Group & IBW (gr) & FBW (gr) & HW (mg) & $\mathrm{HWI}(\mathrm{mg} / \mathrm{g})$ \\
\hline Control & $221.4 \pm 4.5$ & $244.9 \pm 6.1$ & $756.1 \pm 44.7$ & $3.08 \pm 0.11$ \\
\hline DOX & $220.8 \pm 7.5$ & $202.7 \pm 6.3^{\star \star \star}$ & $663.7 \pm 25.3^{\star \star \star}$ & $3.27 \pm 0.06^{\star \star \star}$ \\
\hline DOX-P-MNPs & $223.7 \pm 6.1$ & $212.0 \pm 6.2^{\star \star \star \#}$ & $718.0 \pm 28.8^{\# \#}$ & $3.38 \pm 0.07^{\star \star \star \#}$ \\
\hline DOX-FA-P-MNPs & $221.9 \pm 8.9$ & $214.2 \pm 9.2^{\star \star \star \# \#}$ & $773.6 \pm 46.8^{\# \# \#}$ & $3.42 \pm 0.10^{\star \star \star \# \#}$ \\
\hline \multicolumn{5}{|c|}{$\begin{array}{l}\text { Initial body weight (IBW), final body weight (FBW), heart weight }(\mathrm{HW}) \text {, and heart weight index (HWI) } \\
\text { are shown in the study groups. Data are expressed as mean } \pm \text { SD }(n=10) ;{ }^{* \star \star} p<0.001 \text { vs. control } \\
\text { group; }{ }^{\#} p<0.05,{ }^{\# \#} p<0.01 \text {, and }{ }^{\# \# \# ~} p<0.001 \text { vs. DOX group. }\end{array}$} \\
\hline
\end{tabular}

\section{Histopathological analysis}

Histopathological examinations of the left ventricular myocardium in the experimental groups are shown in Fig. 3. Morphological evidence showed no significant pathological changes in the DOX loaded into tumor-targeted DDSs. Several changes were detected in the DOX group, such as interstitial edema, hyaline degeneration, mild cardiac fibrosis, focal to extensive hemorrhage, and inflammatory cell infiltration. Notably, the cardiomyopathy (CMY) severity scores of the DOX loaded into tumor-targeted DDSs demonstrated a significant decrease in myocardial injury, including hyaline degeneration, interstitial edema, and inflammatory cell infiltration compared to the DOX group (Fig. 3e).

\section{Gene expression analysis}

\section{Morphological analysis of apoptotic damage in cardiac tissue}

In this study, TUNEL staining was used to determine the effect of tumor-targeting DDSs on the apoptotic cells. As shown in Fig. 4, the DOX group increased triggered cell apoptosis compared to the control $(p<$ 0.001). However, DNA fragmentation decreased significantly in the DOX-folate-poly-MNPs group compared to the DOX group $(\mathrm{p}<0.05)$.

\section{Evaluation of apoptotic genes expression after tumor- targeting drug delivery systems}

In this study, the relative mRNA levels of Bcl-2, BAX, PARP1, and caspase-3 in ventricle tissues were determined by qRT-PCR. The expression levels of target genes were normalized to the reference gene ( $\beta$ actin). 
As shown in Fig. 5, the mRNA level of BAX increased significantly in the DOX group compared to the control group ( $<<0.01$; Fig. $5 a$ ). However, the mRNA level of BAX was reduced significantly in the DOXfolate-poly-MNPs group compared to the DOX group ( $p<0.05$; Fig. $5 a)$. The relative mRNA expression level of antiapoptotic Bcl-2 in the DOXfolatepoly-MNPs group was significantly increased in contrast to the DOX group ( $<<0.01$; Fig. $5 b)$.

The PARP1 mRNA level statistically increased in the DOX group compared to the control $(p<0.001)$, whereas it decreased significantly in the DOX-folate-poly-MNPs group relative to the DOX group $(p<0.01$; Fig. 6a). The caspase-3 mRNA level significantly increased in the DOX group in comparison with the control group $(p<0.001)$, whereas it significantly decreased in the DOX-folate-poly-MNPs group relative to the DOX group ( $p<0.05$; Fig. $6 b)$.

Moreover, the apoptotic protein expression levels in the ventricle tissue were detected by a Western blot and normalized with $\beta$-actin. As shown in Fig. $5 d$, the DOX, DOX-poly-MNPs and DOX-folate-poly-MNPs groups induced the upregulation of BAX protein levels compared to the control group $(p<0.001, p<0.01$, $p<0.05$, respectively). In contrast, the DOX-poly-MNPs and DOX-folate-poly-MNPs groups reduced BAX protein expression levels compared to the DOX group $(\mathrm{p}<0.01, \mathrm{p}<0.001)$. The anti-apoptotic $\mathrm{Bcl}-2$ protein expression levels in the DOXpolyMNPs and DOXfolate-poly-MNPs groups significantly increased compared to the DOX group ( $p<0.05, p<0.01$; Fig. $5 d$ ). However, the BAX/Bcl-2 ratio significantly decreased in both DOX loaded into tumor-targeted DDSs groups in comparison to the DOX group $(\mathrm{p}<0$. 001; Fig. 5e).

However, the cleaved-PARP1 protein expression decreased in the DOX-poly-MNP and DOXfolate-polyMNPs groups compared to the DOX group ( $<<0.01, p<0.001$; Fig. $6 d$ ). Also, the cleaved-PARP1/PARP1 ratio significantly decreased in both DOX loaded into tumortargeted DDSs compared to the DOX group (Fig. 6e). In addition, the reduced protein expression of cleaved-caspase-3 confirmed that the cell death level decreased in both DOX loaded into tumor-targeted DDSs treated rats compared to the DOX group (Fig. 6f). Consequently, the cleaved-caspase-3/caspase-3 ratio in the DOX-poly-MNPs and DOXfolatepolyMNPs groups decreased significantly compared to the DOX group $(p<0.05, p<0.01$; Fig. $6 \mathrm{~g}$ ). The protein levels of $\beta$-actin were similar in all groups.

\section{Evaluation of NLRP3 inflammasome-mediated inflammation after tumor-targeting drug delivery systems}

The pyroptosis effect of DOX on cardiomyocytes was investigated via the NLRP3-caspase-1 pathway. In this study, the protein expression levels of ASC, caspase-1, IL-1 3 , and IL-18 in the ventricle tissues were determined by a Western blot assay and normalized to $\beta$-actin. DOXtreated animals showed elevated protein expression of ASC, c-caspase-1, c-IL-1 $\beta$, and CIL-18 compared to the control $(p<0.001$; Fig. 7$)$. However, in the DOX-folate-poly-MNPs group, the protein expression of ASC, c-caspase-1, c-IL-1 $\beta$, and c-IL18 was reduced significantly compared to the DOX group (Fig. 7). In addition, the ccaspase-1/procaspase-1 ratio in the DOX-folate-poly-MNPs group was decreased in comparison with the DOX group ( $p$ $<0.05$; Fig. 7d). 


\section{Discussion}

The effective conjugation of chemotherapeutic drugs, imaging agents, and tumor-targeting ligands into nanoparticles has been extensively applied to provide diagnostic agents for selective cancer chemotherapy (Morales-Cruz et al., 2019, Navya et al., 2019). Generally, in DDSs, if the size of nanocarriers is less than $100 \mathrm{~nm}$, it will be appropriate for the transit of pores on the cell surface formed by the regulation of osmolarity at a size of 10-500 nm (Gupta et al., 2014). Thermo and pH dualresponsive polymer nanoparticles have demonstrated considerable anticancer properties in the controlled release of drugs due to lower $\mathrm{pH}$ and higher tumor temperatures than normal tissues (Lanzalaco and Armelin, 2017, Oroojalian et al., 2018).

Likewise, the folate-targeted nanoparticles have been extensively used in active targeting for effective cancer treatment due to the folate-dependent cellular internalization mechanism by FOLR1 binding (Li et al., 2011, Li et al., 2015, Ndong et al., 2015, Ak et al., 2018). Recent studies have shown that if a folic acid is conjugated with a pH-sensitive nanocarrier, it could act as a targeting moiety to facilitate receptormediated endocytosis to cancer cells, improve targeted drug delivery, increase DOX accumulation and release in the tumor tissue, and ultimately reduce tumor growth and adverse effects following DOX chemotherapy (Banu et al., 2015, Ak et al., 2018, Kanwal et al., 2018).

DIC is characterized by a number of abnormalities, including myopericarditis, dysrhythmia, electrocardiographic repolarization changes, troponin elevation, and systolic or diastolic ventricular dysfunction, which may be predisposed to dilated cardiomyopathy (DCM) or congestive heart failure (CHF) several days to one year after chemotherapy (Jain et al., 2017). A previous study demonstrated that DOX-folate-conjugated poly (NIPAAm-co-IA) @Fe304 NPs and DOXpoly (NIPAAm-co-IA) @Fe304 NPs could significantly improve the antitumor effects in HeLa cell (FR-positive) and A549 cell (FR-negative) (Ghorbani et al., 2016). In this study, further in vivo studies were conducted on the breast cancer model to reduce the adverse effects of DOX chemotherapy by increasing selectivity and controlling release at lower $\mathrm{pH}$ and higher tumor tissue temperatures. Therefore, poly-MNPs and folate-poly-MNPs were used to evaluate whether passive and active tumor-targeting of DOX might protect cardiotoxicity while not affecting the antitumor activity of DOX in the breast cancer model.

The ECG is a simple, non-invasive, and accessible technique used for tracing cardiotoxicity in clinical practice (Drew et al., 2004). Previous studies have shown that the most common ECG changes in the DOX cardiotoxicity, including QRS complex, QT, and QTc interval prolongation, could predict a high risk of developing malignant ventricular arrhythmias (Cai et al., 2019). However, the findings of this study demonstrated that loading DOX into tumor-targeted DDSs showed a considerable improvement in ECG parameters, including heart rate, RR interval, PR interval, QRS complex, QTc interval, and QT interval compared to the DOX group.

DOX chemotherapy significantly attenuates cardiac function by inducing ROS generation, disruption of calcium homeostasis, and decreases in SA node excitability in the cardiac conducting system, leading to decreased cardiac function (Kim et al., 2006, Shi et al., 2018). To assess hemodynamic function, arterial 
blood pressure and left ventricular functions were analyzed in the study groups. However, DOX treatment with novel targeted nanocarriers improved SAP, DAP, MAP, min pressure, max pressure, mean pressure, the EDP index, contractility index, min $\mathrm{dP} / \mathrm{dt}$, and max $\mathrm{dP} / \mathrm{dt}$ compared to the DOX group. The results of the present study were consistent with previous studies that examined DIC, ECG pattern abnormalities, left ventricular dysfunction, and decreased blood pressure parameters (Octavia et al., 2012, Razmaraii et al., 2016c). Moreover, it is generally accepted that DIC is associated with a reduction in the heart to body weight ratio (Ghibu et al., 2012, Swamy et al., 2012, Arafa et al., 2014, Razmaraii et al., 2016b). In contrast, the rats treated with DOX loaded into tumor-targeted DDSs experienced a significant increase in $\mathrm{HWI}$ and final body weight compared to the DOX group, but there was no statistically significant difference in the heart weight as compared to the control group $(p>0.05)$.

Likewise, histopathological results of the left ventricular myocardium were consistent with prior studies that described DOX-induced cardiac abnormalities such as cytoplasmic vacuolization, hyaline degeneration, interstitial edema, inflammatory cell infiltration, mild cardiac fibrosis, focal to extensive hemorrhage, and cardiomyocyte necrosis following DOX administration (Razmaraii et al., 2016a). Notably, the histopathological findings and the cardiomyopathy severity scores confirmed that the tumortargeting DDSs significantly reduced cardiac structural abnormalities, including interstitial edema, hyaline degeneration, and inflammatory cell infiltration compared to the DOX group. The results of this study revealed that hemodynamic function, $\mathrm{HWI}$, and cardiomyopathy severity scores in the novel targeted DDSs were effective in protecting against DIC in the experimental groups.

Irreversible LV dysfunction and myocardial cell death were associated with DOXinduced cardiotoxicity following breast cancer therapy (Zhang et al., 2009, Kumar et al., 2012). A similar study suggested that cardiac health monitoring would be determined by a significant decrease in heart weight and increased apoptosis in the TUNEL assay (Adão et al., 2013). In this study, TUNEL staining confirmed that DNA fragmentation and apoptotic cells in the tumor-targeting DDSs decreased compared to the DOX group.

Previous studies have demonstrated that mitochondrial damage plays a critical role in the initiation of apoptosis in cardiomyocytes due to the release of cytochrome c, cleaved-caspase-3, cleaved-PARP1, and AMP-activated protein kinase. The cleavage of PARP (C-PARP1) is a prominent feature of cell death, occurring in two different pathways; a lysosomal protease cleaves PARP to a 55-kDa C-PARP1 protein in the necrotic pathway, and caspase-3 cleaves PARP to an 89-kDa C-PARP1 protein in the apoptosis pathway (Sosna et al., 2014, Shin et al., 2015, Morris et al., 2018). Several in vivo studies indicated that the accumulation of DOX with folate nanocarriers decreased in cardiac tissue due to the EPR effect and folate-receptor-mediated endocytosis while reducing the concentration of DOX in the bloodstream and maintaining a higher concentration of DOX in the tumor tissue (Yoo and Park, 2004, Li et al., 2011, Li et al., 2015, Ndong et al., 2015, Ak et al., 2018). In addition, the results of DIC studies confirmed that DOX treatment led to increased free radicals, decreased gene expression of $\mathrm{Bcl}-2$, and increased gene expression of BAX, PARP1, caspase-3, and the BAX/Bcl-2 ratio (Yoo and Park, 2004, Sun et al., 2016). 
As shown in Figures 4-6, the results of this study indicated that DOX-folate-poly-MNPs administration could inhibit apoptosis by reducing the protein expression levels of BAX, CPARP1, ccaspase-3, and the $\mathrm{BAX} / \mathrm{Bcl}-2$ ratio compared to the DOX group. Moreover, these novel tumor-targeting DDSs could prevent apoptosis in cardiac tissue by decreasing the ccaspase-3/caspase-3 and c-PARP1/PARP1 protein expression levels compared to the DOX group.

A previous study demonstrated that the inactivated PARP1 protected the heart against ROS generated, myocardial apoptosis, and cardiac dysfunction (Bartha et al., 2011). However, in the DOX-folate-polyMNPs group, the protein expression of c-PARP1 (89kDa) was reduced compared to the DOX group. Besides, in a similar study, the biodistribution profiles of DOXFA-PEG-P (HB-HO) NPs, DOXP (HB-HO) NPs, and free DOX in cardiac tissue were measured for up to 48 hours. The cardiac accumulation of DOX was significantly reduced in DOX-FA-PEG-P ( $\mathrm{HBHO})$ NPs treated mice, whereas the DOX content in tumors and the halflife of DOX-P (HB-HO) NPs increased compared to free DOX (Zhang et al., 2016).

Recent research has shown that DOX treatment causes pyroptosis in cardiomyocytes, an inflammatory caspases-dependent programmed cell death via the NLRP3-caspase-1 pathway (Meng et al., 2019). The NLRP3 inflammasome is composed of a large protein complex of NLRP3, ASC, and pro-caspase-1. The adaptor ASC and pro-caspase-1 are recruited when the NLRP3 inflammasome is activated. Then, activated caspase-1 processes the maturation and release of IL-1 $13, \mathrm{IL}-18$, and gasdermin $\mathrm{D}$. The $\mathrm{N}$ terminal cleavage fragment of gasdermin $D$ induces pyroptosis by forming plasma membrane pores, causing cell swelling, plasma membrane rupture, and the secretion of proinflammatory cytoplasmic contents, inflammatory responses, cardiomyocyte death, and cardiac damage (Meng et al., 2019, Zeng et al., 2020, Liu et al., 2021). As DOX induces cardiomyocyte by activating the NLRP3-caspase-1 pathway, our findings suggest that the novel targeting DDS causes less cardiotoxicity than the free DOX and inhibits NLRP3-mediated pyroptosis in vivo by downregulating ASC, c-caspase-1, c-IL-1 $\beta$, and c-IL-18 protein expression levels compared to the DOX group. In addition, the c-caspase-1/pro-caspase-1 ratio in the DOX-folate-poly-MNPs group was reduced in comparison with the DOX group. Similarly, the findings of NLRP3 inflammasome-mediated inflammation following tumortargeting DDSs confirmed the histopathological results of the left ventricular myocardium, which showed that the novel targeted DDSs reduced inflammatory cell infiltration and cardiomyopathy severity scores as compared to the DOX group.

The results of this study are in agreement with previous in vivo studies, which suggested that the synergistic antitumor effects of passive and active targeting DDSs in the tumor tissues might be attributed to decreased DOX exposure in the cardiac tissues (Huang et al., 2016, Ma et al., 2017, Hyun et al., 2019). Therefore, the cardiac health monitoring following breast cancer therapy confirmed that administration of DOX-folate-poly-MNPs, a tumor-targeting DDSs, could decrease irreversible LV dysfunction, myocardial cell death, and DNA fragmentation in the cardiac tissue by decreasing the protein expressions of BAX, c-PARP1, c-caspase-3, and the BAX/Bcl-2 ratio compared to the DOX group. Finally, these facts suggest that the folatepolyMNPs could be a desirable nanocarrier for the tumortargeting drug delivery of DOX, capable of reducing DIC and improving the efficacy of chemotherapy in a breast cancer model rather than commercial DOX therapy. 


\section{Conclusion}

To overcome the nonspecific distribution in normal tissues, the novel tumor-targeting DDSs were studied to reduce DOX-cardiotoxicity in the animal breast cancer model. As expected, the results of this study confirmed that DOX-folate-poly-MNPs improved the hemodynamic parameters, including ECG, blood pressure, left ventricular function, and heart weight index $(\mathrm{HWI})$, compared to the commercial DOX. According to histopathological examinations, qRTPCR, western blotting, and TUNEL assays, the novel tumor-targeting DDSs with folate indicated no significant alterations in cardiomyocyte apoptotic signaling following DOX treatment. Moreover, it could decrease irreversible LV dysfunction, myocardial cell death, and DNA fragmentation in the cardiac tissue by decreasing the protein expression levels of BAX, cPARP1, ccaspase 3, and also downregulation of the BAX to Bcl-2, c-PARP1/PARP1, and ccaspase3 /caspase-3 ratios compared to the commercial DOX. Further investigations demonstrated that DOXfolate-poly-MNPs could inhibit pyroptosis via the NLRP3-caspase-1 pathway and also inhibit overexpression of ASC, caspase-1, IL-1 13 , and IL-18 protein expression levels to prevent myocardial damage. Therefore, the developed folate-poly-MNPs with confirmed reduced cardiotoxicity could be proposed as a potential tumor-targeted nanocarrier for an effective DOX delivery system.

\section{Declarations}

\section{Acknowledgments}

The work was supported by Tabriz University of Medical Sciences, Iran (grant number, 58175). The authors would like to acknowledge the Drug Applied Research Center and the Immunology Research Center for their laboratory support in this research, especially Dr. Yari Khosroshahi, Dr. Heydari, Dr. Azimian, and Dr. Nasseri. This research was part of a Ph.D. thesis carried out by Nasibeh Mohammad Ali Pourradi (NO: 1396.492).

\section{Author contribution}

Y.A and H.H designed the research. H.B, B.B and B.SH conducted the experiments. Y.A, N.M.A.P, and Z.A analyzed the data. N.M.A.P wrote and Y.A revised the manuscript. All authors read and approved the manuscript.

Availability of data and materials: Available on request.

Code availability: Not applicable

Ethics Approval: The animals used for the experiments were conducted with approval from the Institutional Animal Ethics Committee at Tabriz University of Medical Sciences (Approval number: IR.TBZMED.REC.1396.492).

Consent to participate: Not applicable. 
Consent for publication: Not applicable.

Conflict of interest: The authors declare no conflicts of interest.

\section{References}

1. Adão R, de Keulenaer G, Leite-Moreira A, Brás-Silva C (2013) Cardiotoxicity associated with cancer therapy: Pathophysiology and prevention. Revista Portuguesa de Cardiologia (English Edition) 32: 395-409

2. Ak G, Yilmaz H, Gunes A, Hamarat Sanlier S (2018) In vitro and in vivo evaluation of folate receptortargeted a novel magnetic drug delivery system for ovarian cancer therapy. Artif Cells Nanomed Biotechnol 46: 926-937

3. Arafa MH, Mohammad NS, Atteia HH, Abd-Elaziz HR (2014) Protective effect of resveratrol against doxorubicin-induced cardiac toxicity and fibrosis in male experimental rats. Journal of physiology and biochemistry 70: 701-711

4. Banu H, Sethi DK, Edgar A, Sheriff A, Rayees N, Renuka N, Faheem SM, Premkumar K, Vasanthakumar G (2015) Doxorubicin loaded polymeric gold nanoparticles targeted to human folate receptor upon laser photothermal therapy potentiates chemotherapy in breast cancer cell lines. Journal of Photochemistry and Photobiology B: Biology 149: 116-128

5. Bartha E, Solti I, Szabo A, Olah G, Magyar K, Szabados E, Kalai T, Hideg K, Toth K, Gero D (2011) Regulation of kinase cascade activation and heat shock protein expression by poly (ADP-ribose) polymerase inhibition in doxorubicin-induced heart failure. Journal of cardiovascular pharmacology 58: 380-391

6. Bertrand N, Wu J, Xu X, Kamaly N, Farokhzad OC (2014) Cancer nanotechnology: the impact of passive and active targeting in the era of modern cancer biology. Advanced drug delivery reviews 66: 2-25

7. Burridge PW, Li YF, Matsa E, Wu H, Ong S-G, Sharma A, Holmström A, Chang AC, Coronado MJ, Ebert AD (2016) Human induced pluripotent stem cell-derived cardiomyocytes recapitulate the predilection of breast cancer patients to doxorubicin-induced cardiotoxicity. Nature medicine 22: $547-$ 547

8. Cai F, Luis MAF, Lin X, Wang M, Cai L, Cen C, Biskup E (2019) Anthracycline-induced cardiotoxicity in the chemotherapy treatment of breast cancer: Preventive strategies and treatment. Molecular and Clinical Oncology 11: 15-23

9. Cappetta D, Rossi F, Piegari E, Quaini F, Berrino L, Urbanek K, De Angelis A (2018) Doxorubicin targets multiple players: a new view of an old problem. Pharmacological research 127: 4-14

10. Drew BJ, Califf RM, Funk M, Kaufman ES, Krucoff MW, Laks MM, Macfarlane PW, Sommargren C, Swiryn S, Van Hare GF (2004) Practice standards for electrocardiographic monitoring in hospital settings: an American Heart Association scientific statement from the Councils on Cardiovascular Nursing, Clinical Cardiology, and Cardiovascular Disease in the Young: endorsed by the International 
Society of Computerized Electrocardiology and the American Association of Critical-Care Nurses. Circulation 110: 2721-2746

11. Ghibu S, Delemasure S, Richard C, Guilland J-C, Martin L, Gambert S, Rochette L, Vergely C (2012) General oxidative stress during doxorubicin-induced cardiotoxicity in rats: absence of cardioprotection and low antioxidant efficiency of alpha-lipoic acid. Biochimie 94: 932-939

12. Ghorbani M, Hamishehkar H, Arsalani N, Entezami AA (2016) Surface decoration of magnetic nanoparticles with folate-conjugated poly ( $\mathrm{N}$-isopropylacrylamide-co-itaconic acid): A facial synthesis of dual-responsive nanocarrier for targeted delivery of doxorubicin. International Journal of Polymeric Materials and Polymeric Biomaterials 65: 683-694

13. Greish K (2010) Enhanced permeability and retention (EPR) effect for anticancer nanomedicine drug targeting. Springer, pp. 25-37

14. Gupta N, Patel B, Ahsan F (2014) Nano-engineered erythrocyte ghosts as inhalational carriers for delivery of fasudil: preparation and characterization. Pharmaceutical research 31: 1553-1565

15. Hartmann LC, Keeney GL, Lingle WL, Christianson TJH, Varghese B, Hillman D, Oberg AL, Low PS (2007) Folate receptor overexpression is associated with poor outcome in breast cancer. International journal of cancer 121: 938-942

16. He Z, Zhang Y, Khan AR, Ji J, Yu A, Zhai G (2021) A novel progress of drug delivery system for organelle targeting in tumour cells. Journal of drug targeting 29: 12-28

17. Huang Y, Cole SPC, Cai T, Cai YU (2016) Applications of nanoparticle drug delivery systems for the reversal of multidrug resistance in cancer. Oncology letters 12: 11-15

18. Hyun H, Lee S, Lim W, Jo D, Jung JS, Jo G, Kim SY, Lee D-W, Um S, Yang DH (2019) Engineered betacyclodextrin-based carrier for targeted doxorubicin delivery in breast cancer therapy in vivo. Journal of Industrial and Engineering Chemistry 70: 145-151

19. Jain D, Russell RR, Schwartz RG, Panjrath GS, Aronow W (2017) Cardiac complications of cancer therapy: pathophysiology, identification, prevention, treatment, and future directions. Current cardiology reports 19: 36-36

20. Kanwal U, Irfan Bukhari N, Ovais M, Abass N, Hussain K, Raza A (2018) Advances in nano-delivery systems for doxorubicin: an updated insight. Journal of drug targeting 26: 296-310

21. Khan MS, Singh M, Khan MA, Arya D, Ahmad S (2014) Scientific validation of cardioprotective attribute by standardized extract of Bombyx mori against doxorubicin-induced cardiotoxicity in murine model. EXCLI journal 13: 1043

22. Kim S-Y, Kim S-J, Kim B-J, Rah S-Y, Chung SM, Im M-J, Kim U-H (2006) Doxorubicin-induced reactive oxygen species generation and intracellular $\mathrm{Ca} 2+$ increase are reciprocally modulated in rat cardiomyocytes. Exp Mol Med 38: 535-545

23. Kumar S, Marfatia R, Tannenbaum S, Yang C, Avelar E (2012) Doxorubicin-induced cardiomyopathy 17 years after chemotherapy. Texas Heart Institute Journal 39: 424-424

24. Lanzalaco S, Armelin E (2017) Poly (n-isopropylacrylamide) and copolymers: A review on recent progresses in biomedical applications. Gels 3: 36-36 
25. Latifi Z, Fattahi A, Hamdi K, Ghasemzadeh A, Karimi P, Nejabati HR, Novin MG, Roshangar L, Nouri M (2018) Wnt signaling pathway in uterus of normal and seminal vesicle excised mated mice during pre-implantation window. Geburtshilfe und Frauenheilkunde 78: 412-412

26. Li X, Tian X, Zhang J, Zhao X, Chen X, Jiang Y, Wang D, Pan W (2011) In vitro and in vivo evaluation of folate receptor-targeting amphiphilic copolymer-modified liposomes loaded with docetaxel. International journal of nanomedicine 6: 1167-1167

27. Li Y-J, Dong M, Kong F-M, Zhou J-P (2015) Folate-decorated anticancer drug and magnetic nanoparticles encapsulated polymeric carrier for liver cancer therapeutics. International journal of pharmaceutics 489: 83-90

28. Liu J, Jin Y, Wang B, Wang Y, Zuo S, Zhang J (2021) Dopamine D1 receptor alleviates doxorubicininduced cardiac injury by inhibiting NLRP3 inflammasome. Biochem Biophys Res Commun 561: 7-13

29. Ma W, Guo Q, Li Y, Wang X, Wang J, Tu P (2017) Co-assembly of doxorubicin and curcumin targeted micelles for synergistic delivery and improving anti-tumor efficacy. European Journal of Pharmaceutics and Biopharmaceutics 112: 209-223

30. McGowan JV, Chung R, Maulik A, Piotrowska I, Walker JM, Yellon DM (2017) Anthracycline chemotherapy and cardiotoxicity. Cardiovascular drugs and therapy 31: 63-75

31. Meng L, Lin H, Zhang J, Lin N, Sun Z, Gao F, Luo H, Ni T, Luo W, Chi J (2019) Doxorubicin induces cardiomyocyte pyroptosis via the TINCR-mediated posttranscriptional stabilization of NLR family pyrin domain containing 3 . Journal of molecular and cellular cardiology 136: 15-26

32. Morales-Cruz M, Delgado Y, Castillo B, Figueroa CM, Molina AM, Torres A, Milián M, Griebenow K (2019) Smart Targeting To Improve Cancer Therapeutics. Drug Design, Development and Therapy 13: $3753-3753$

33. Morris G, Walker AJ, Berk M, Maes M, Puri BK (2018) Cell death pathways: a novel therapeutic approach for neuroscientists. Molecular neurobiology 55: 5767-5786

34. Navya PN, Kaphle A, Srinivas SP, Bhargava SK, Rotello VM, Daima HK (2019) Current trends and challenges in cancer management and therapy using designer nanomaterials. Nano Convergence 6 : 23-23

35. Ndong C, Toraya-Brown S, Kekalo K, Baker I, Gerngross TU, Fiering SN, Griswold KE (2015) Antibodymediated targeting of iron oxide nanoparticles to the folate receptor alpha increases tumor cell association in vitro and in vivo. International journal of nanomedicine 10: 2595-2595

36. Octavia Y, Tocchetti CG, Gabrielson KL, Janssens S, Crijns HJ, Moens AL (2012) Doxorubicin-induced cardiomyopathy: from molecular mechanisms to therapeutic strategies. Journal of molecular and cellular cardiology 52: 1213-1225

37. Oroojalian F, Babaei M, Taghdisi SM, Abnous K, Ramezani M, Alibolandi M (2018) Encapsulation of thermo-responsive gel in $\mathrm{pH}$-sensitive polymersomes as dual-responsive smart carriers for controlled release of doxorubicin. Journal of controlled release 288: 45-61

38. Park JW (2002) Liposome-based drug delivery in breast cancer treatment. Breast Cancer Research 4: 95-95 
39. Payne GF, Raghavan SR (2007) Chitosan: a soft interconnect for hierarchical assembly of nano-scale components. Soft Matter 3: 521-527

40. Raa A, Stansberg C, Steen VM, Bjerkvig R, Reed RK, Stuhr LEB (2007) Hyperoxia retards growth and induces apoptosis and loss of glands and blood vessels in DMBA-induced rat mammary tumors. BMC cancer 7: 23-23

41. Rajendran J, Pachaiappan P, Subramaniyan S (2019) Dose-dependent chemopreventive effects of citronellol in DMBA-induced breast cancer among rats. Drug development research 80: 867-876

42. Razmaraii N, Babaei H, Nayebi AM, Asadnasab G, Helan JA, Azarmi Y (2016a) Cardioprotective effect of phenytoin on doxorubicin-induced cardiac toxicity in a rat model. Journal of cardiovascular pharmacology 67: 237-245

43. Razmaraii N, Babaei H, Nayebi AM, Assadnassab G, Helan JA, Azarmi Y (2016b) Cardioprotective effect of grape seed extract on chronic doxorubicin-induced cardiac toxicity in Wistar rats. Advanced pharmaceutical bulletin 6: 423-423

44. Razmaraii N, Babaei H, Nayebi AM, Assadnassab G, Helan JA, Azarmi Y (2016c) Crocin treatment prevents doxorubicin-induced cardiotoxicity in rats. Life sciences 157: 145-151

45. Saad SY, Najjar TAO, Alashari M (2004) Cardiotoxicity of doxorubicin/paclitaxel combination in rats: effect of sequence and timing of administration. Journal of Biochemical and Molecular Toxicology 18: $78-86$

46. Schiffelers RM, Koning GA, ten Hagen TLM, Fens MHAM, Schraa AJ, Janssen APCA, Kok RJ, Molema G, Storm G (2003) Anti-tumor efficacy of tumor vasculature-targeted liposomal doxorubicin. Journal of controlled release 91: 115-122

47. Shabalala S, Muller CJF, Louw J, Johnson R (2017) Polyphenols, autophagy and doxorubicininduced cardiotoxicity. Life sciences 180: 160-170

48. Shi W, Deng H, Zhang J, Zhang Y, Zhang X, Cui G (2018) Mitochondria-targeting small molecules effectively prevent cardiotoxicity induced by doxorubicin. Molecules 23: 1486

49. Shin H-J, Kwon H-K, Lee J-H, Gui X, Achek A, Kim J-H, Choi S (2015) Doxorubicin-induced necrosis is mediated by poly-(ADP-ribose) polymerase 1 (PARP1) but is independent of p53. Scientific reports 5 : 15798-15798

50. Songbo M, Lang H, Xinyong C, Bin X, Ping Z, Liang S (2019) Oxidative stress injury in doxorubicininduced cardiotoxicity. Toxicology letters 307: 41-48

51. Sosna J, Voigt S, Mathieu S, Lange A, Thon L, Davarnia P, Herdegen T, Linkermann A, Rittger A, Chan FK-M (2014) TNF-induced necroptosis and PARP-1-mediated necrosis represent distinct routes to programmed necrotic cell death. Cellular and molecular life sciences 71: 331-348

52. Sun J, Sun G, Cui X, Meng X, Qin M, Sun X (2016) Myricitrin protects against doxorubicin-induced cardiotoxicity by counteracting oxidative stress and inhibiting mitochondrial apoptosis via ERK/P53 pathway. Evidence-Based Complementary and Alternative Medicine 2016

53. Swamy AV, Gulliaya S, Thippeswamy A, Koti BC, Manjula DV (2012) Cardioprotective effect of curcumin against doxorubicin-induced myocardial toxicity in albino rats. Indian journal of 
pharmacology 44: 73-73

54. Tacar O, Sriamornsak P, Dass CR (2013) Doxorubicin: an update on anticancer molecular action, toxicity and novel drug delivery systems. Journal of pharmacy and pharmacology 65 : 157-170

55. Vicent MJ, Duncan R (2006) Polymer conjugates: nanosized medicines for treating cancer. Trends in biotechnology 24: 39-47

56. Yoo HS, Park TG (2004) Folate receptor targeted biodegradable polymeric doxorubicin micelles. Journal of controlled release 96: 273-283

57. Yu BO, Tai HC, Xue W, Lee LJ, Lee RJ (2010) Receptor-targeted nanocarriers for therapeutic delivery to cancer. Molecular membrane biology 27: 286-298

58. Zeng C, Duan F, Hu J, Luo B, Huang B, Lou X, Sun X, Li H, Zhang X, Yin S (2020) NLRP3 inflammasome-mediated pyroptosis contributes to the pathogenesis of non-ischemic dilated cardiomyopathy. Redox biology 34: 101523

59. Zhang C, Wu Y, Dong Y, Xu H, Zhao L (2016) Quantification of DOX bioavailability in biological samples of mice by sensitive and precise HPLC assay. Pharmaceutical biology 54: 55-61

60. Zhang Y-W, Shi J, Li Y-J, Wei L (2009) Cardiomyocyte death in doxorubicin-induced cardiotoxicity. Archivum immunologiae et therapiae experimentalis 57: 435-445

\section{Figures}




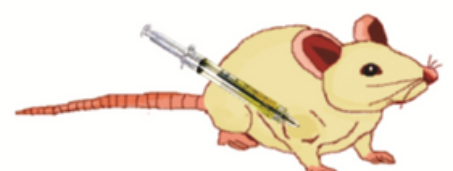

(A)

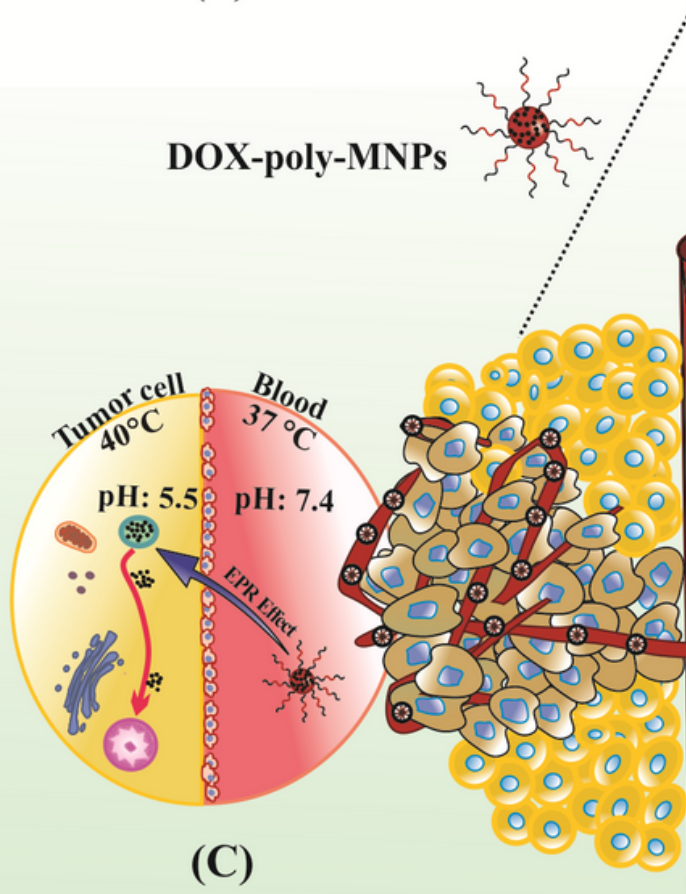

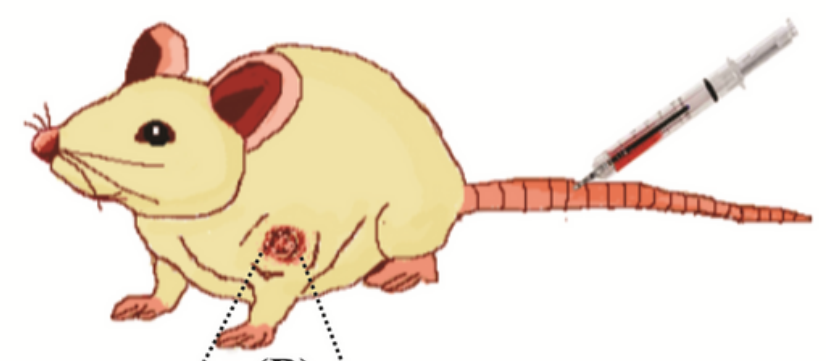

(B)
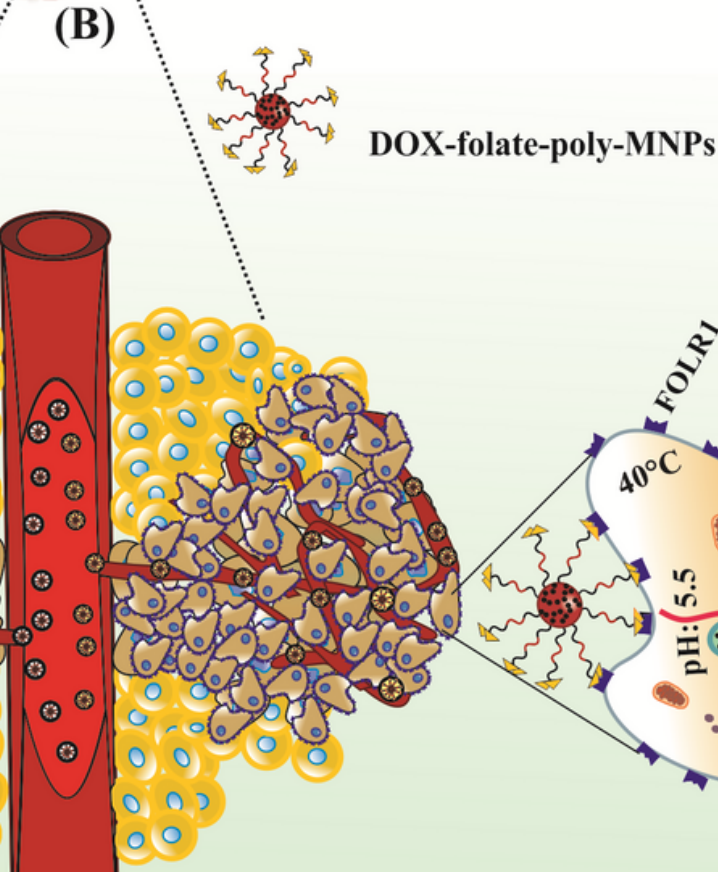<smiles>CCCCC</smiles>

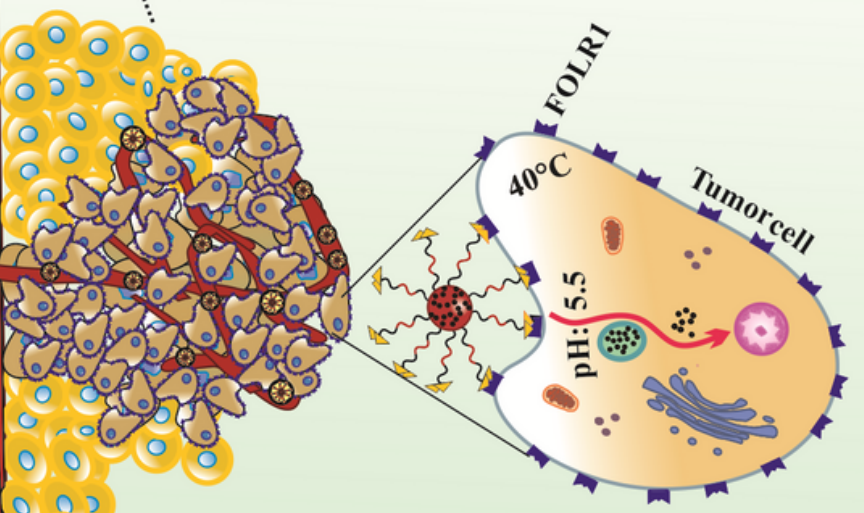

(D)

\section{Figure 1}

Experimental design. a) The induction of mammary tumors in Sprague-Dawley rats by a subcutaneous injection of DMBA at 47 days of age. b) The experiment starts, when the tumor volume reaches 1000 mm3. c) The accumulation of non-targeted nanocarriers by passive targeting through the leaky vasculature at tumor sites. d) The arrival of folate-targeted nanocarriers at tumor sites; they can bind through FRs-mediated endocytosis to cell surface folate receptor (FOLR1) to enter the cells. 


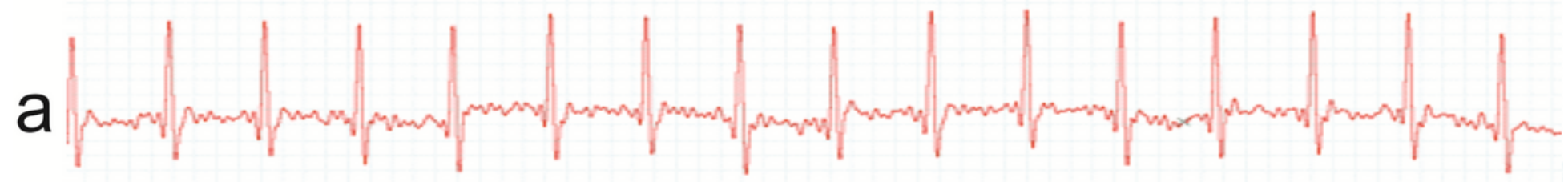
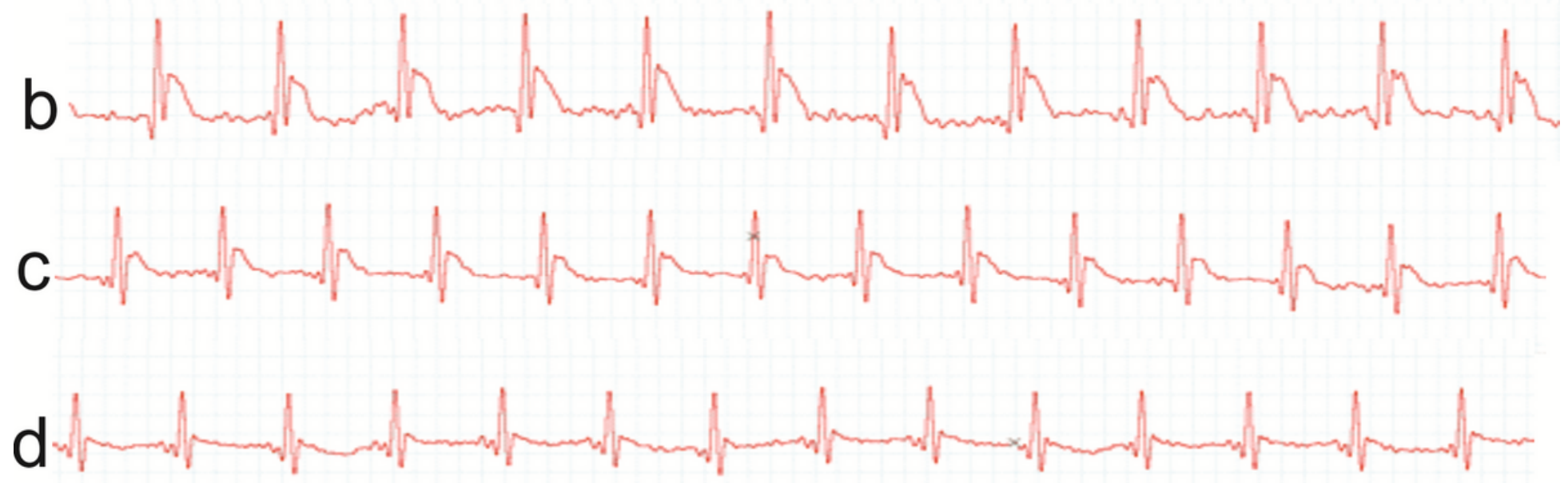

Figure 2

Representative ECGs recorded in the study groups: a) Control, b) DOX, c) DOX poly-MNPs, d) DOX folate poly-MNPs.
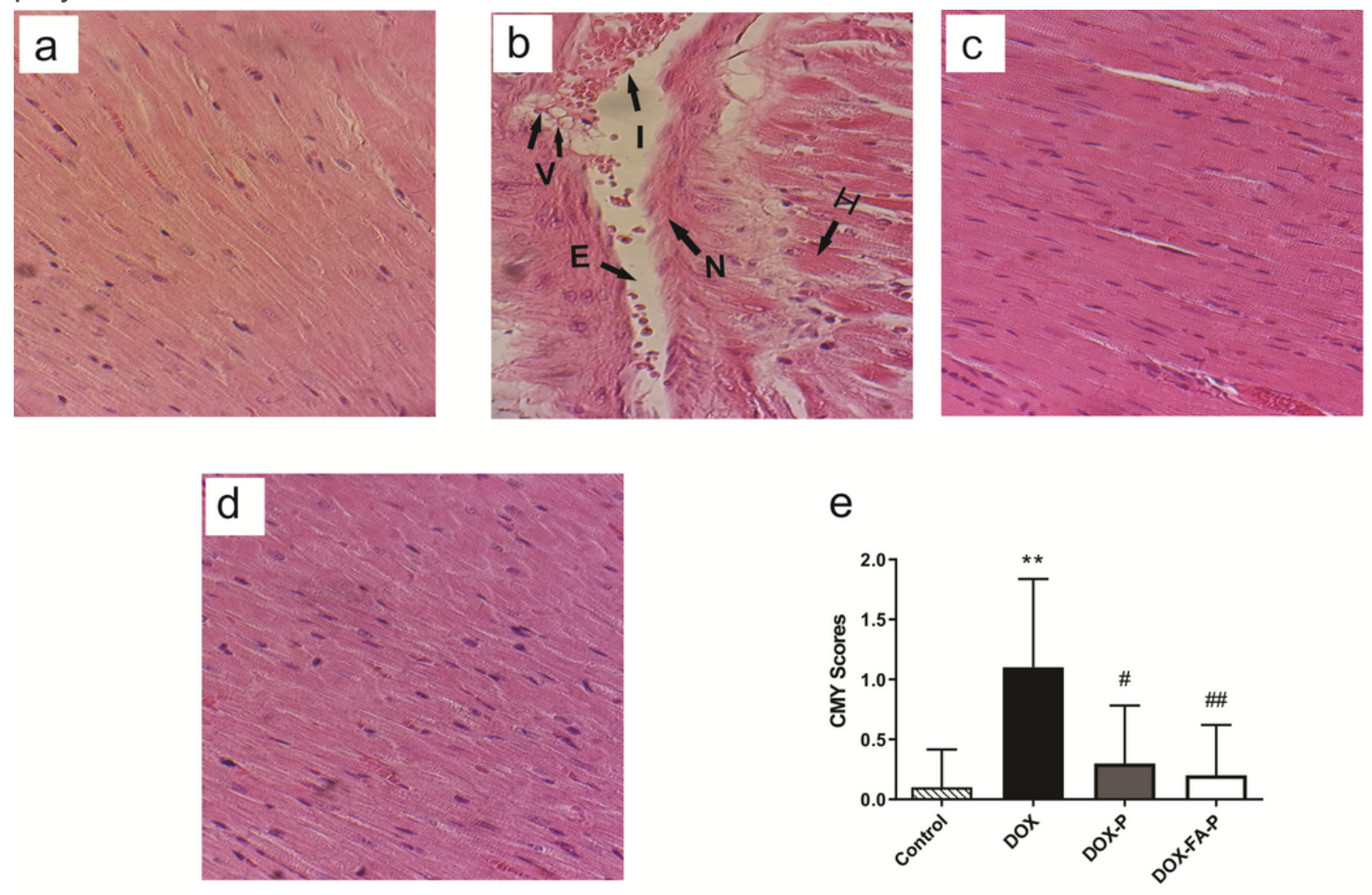

Figure 3 
Histopathological examination of the cardiac tissues (H\&E, 400X). a) Control, c) DOX poly-MNPs, and d) DOX-folate-poly-MNPs groups showed the normal histological appearance of myocardial structures. b) The DOX group showed severe histopathological changes in the structure of the myocardium, such as infiltration of inflammatory cells $(\mathrm{I})$, cytoplasmic myocyte vacuolization $(\mathrm{V})$, hyaline degeneration $(\mathrm{H})$, necrosis $(N)$, and interstitial edema (E). e) The severity scores for cardiomyopathy (CMY) were graded from 0 to 3 as follows: 0 for no damage, 1 for a mild lesion, 2 for a moderate lesion, and 3 or more for a severe lesion. Data are expressed as mean $\pm S D(n=10)$, ** $p<0.01$ vs. control group, $\# p<0.05$ and \#\# $p$ $<0.05$ vs. DOX group.
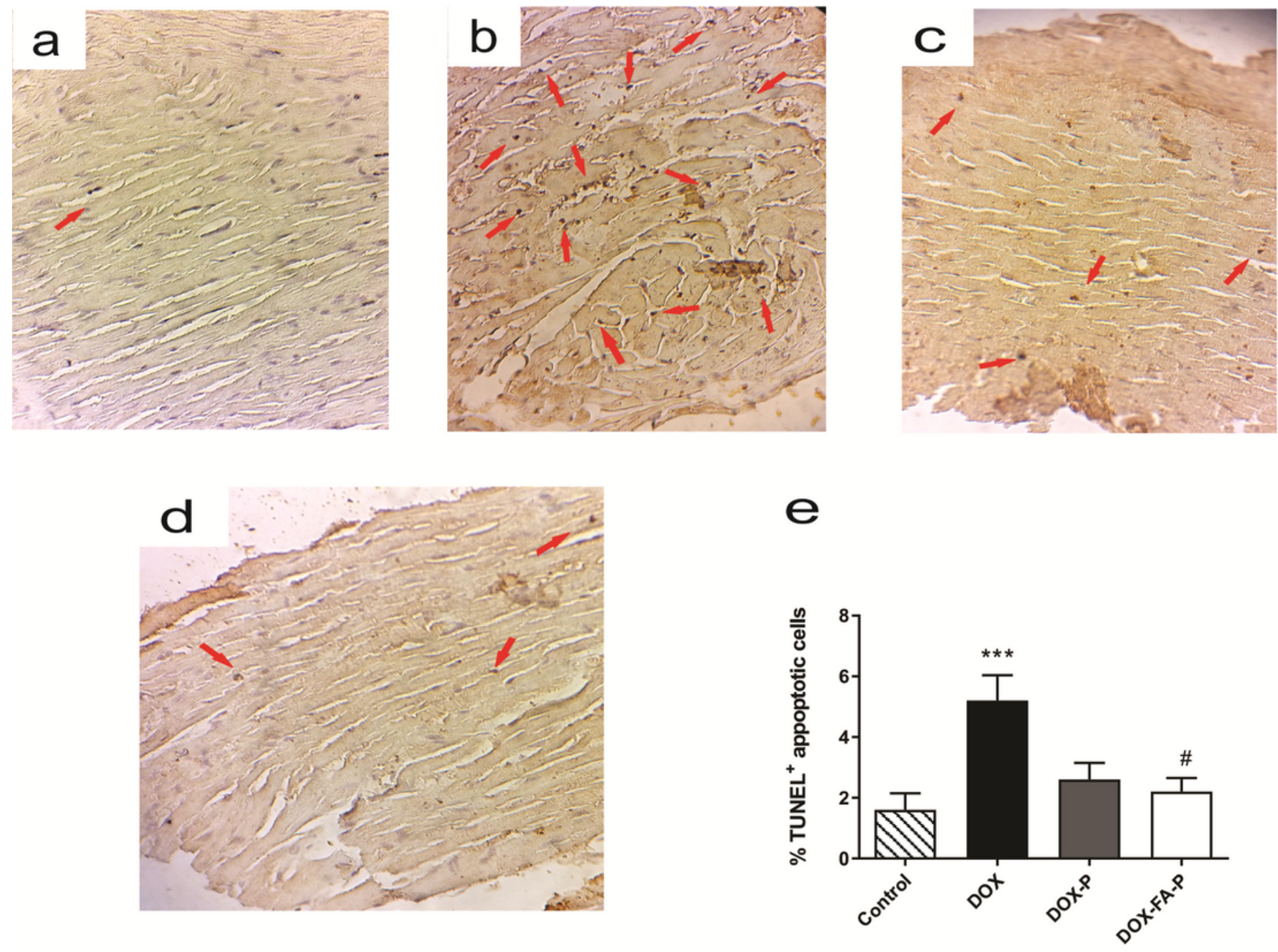

\section{Figure 4}

TUNEL staining in the study groups. Brown-stained nuclei indicated TUNEL-positive cardiomyocytes. a) Control, b) DOX, c) DOX-poly-MNPs, and d) DOX-folate-poly-MNPs. e) \%TUNEL apoptotic cells. Data are expressed as mean \pm SD. $* \star \star p<0.001$ vs. control and \# $p<0.05$ vs. DOX. 
a

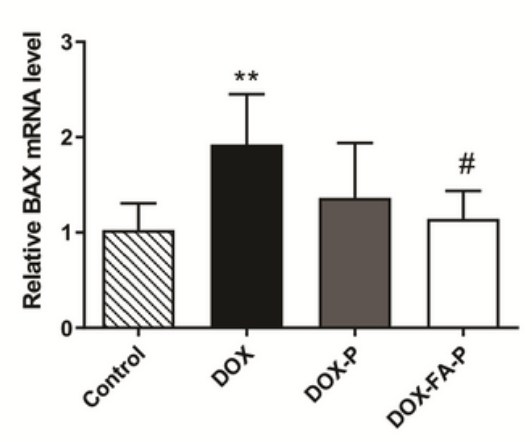

d

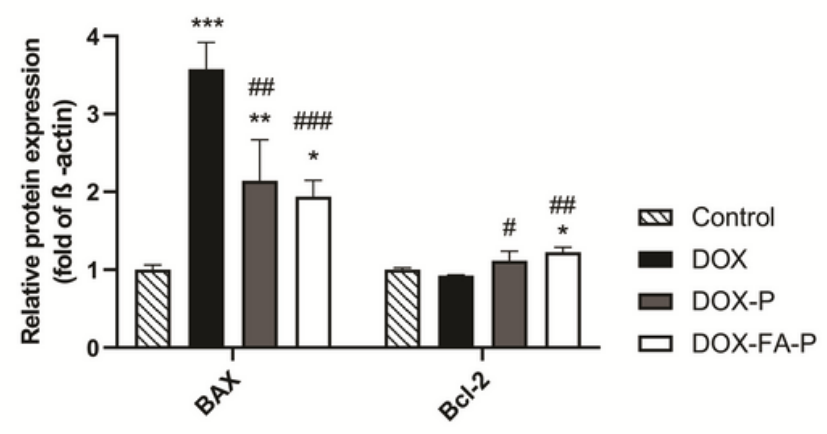

c

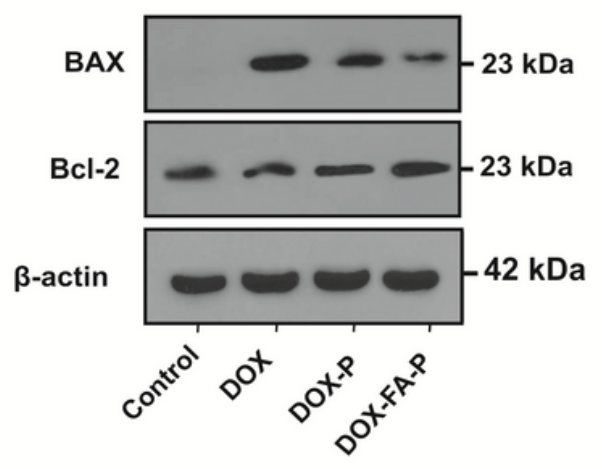

e

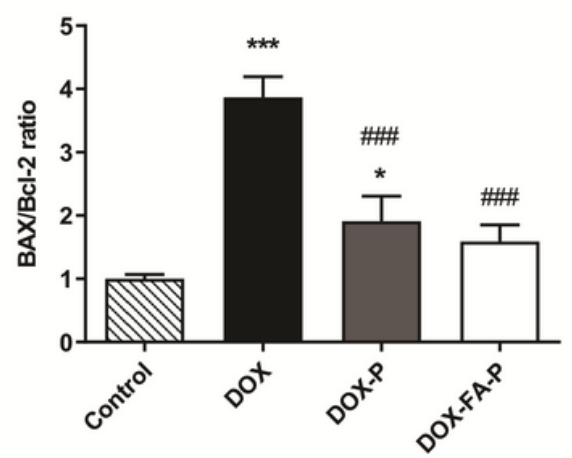

\section{Figure 5}

Expression of apoptosis-related genes in the cardiac tissues. (a) Relative mRNA levels of BAX and (b) Bcl 2 normalized to $\beta$-actinGAPDH. Data are expressed as mean $\pm \operatorname{SD}(n=6)$. $* * p<0.01$ vs. control; $\# p<0.05$ and \#\# $p<0.01$ vs. DOX. (c) Expression of apoptosis-related proteins in the cardiac tissues was detected by western blot. (d) Histograms display the density of BAX and Bcl-2, and (e) the ratio of BAX to Bcl-2 protein expression levels normalized to $\beta$-actinGAPDH. Data are expressed as mean $\pm S D(n=3) . * p<$

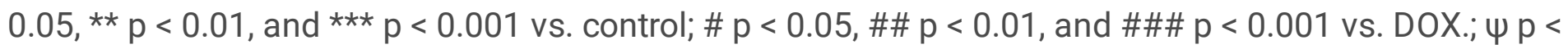
0.05 vs. DOX-poly-MNPs. 
a

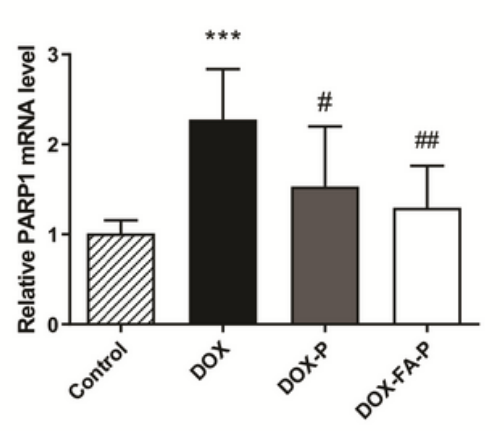

d

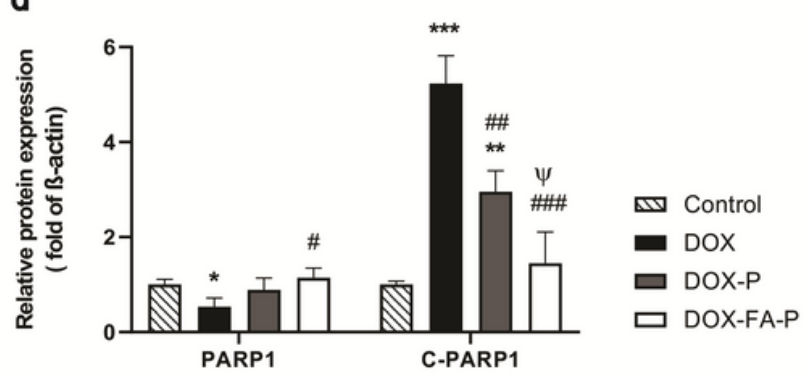

f

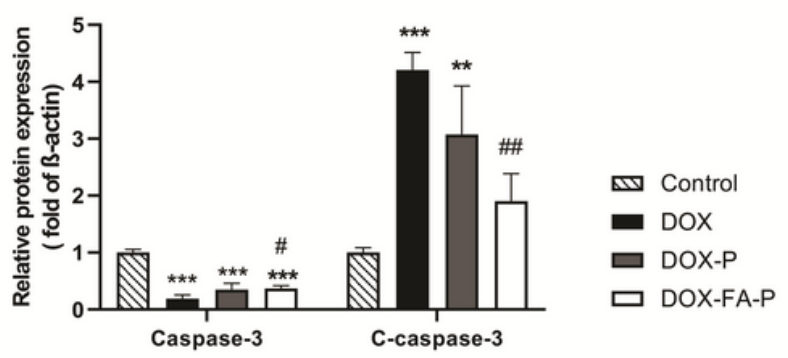

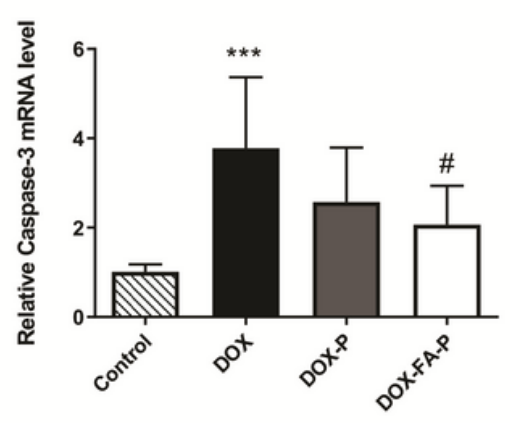

C
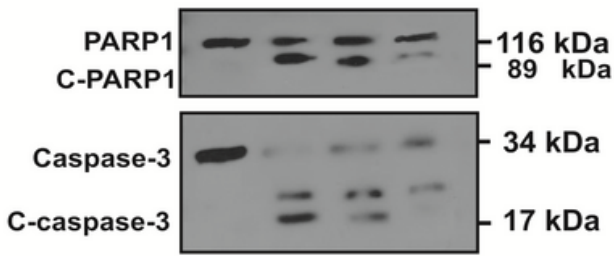

$\beta$-actin

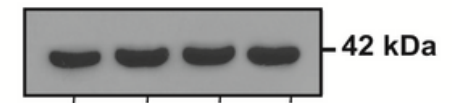

e

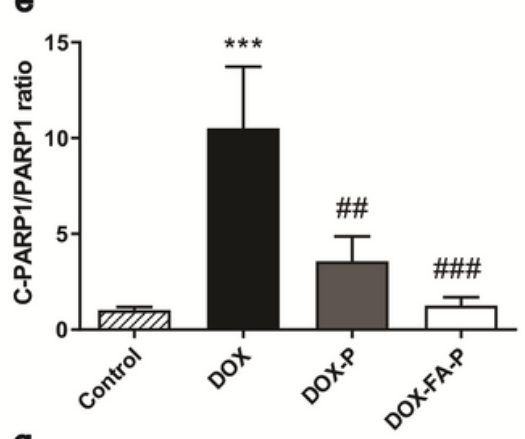

g

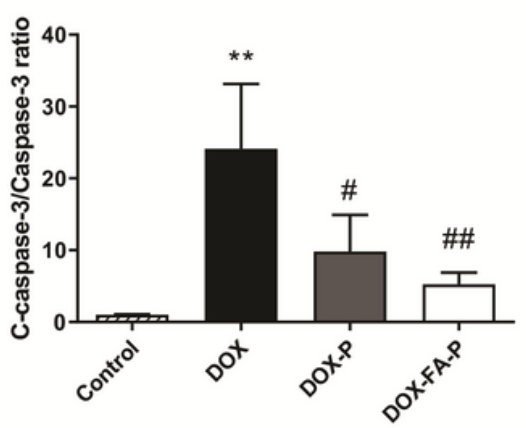

\section{Figure 6}

Expression of apoptosis-related genes in the cardiac tissues. (a) Relative mRNA levels of PARP1 and (b) caspase-3 normalized to $\beta$-actinGAPDH. Data are expressed as mean $\pm S D(n=6)$. *** $p<0.001$ vs. control; \# p< 0.05, \#\# p < 0.01 vs. DOX. (c) Expression of apoptosis-related proteins in the cardiac tissues was detected by western blot. (d) Histograms display the density of PARP1 and C-PARP1, and (e) the ratio of C-PARP1/PARP1 protein expression levels normalized to $\beta$-actinGAPDH. (f) Histograms display the density of caspase-3, c-caspase-3, and (g) the ratio of c caspase 3/caspase-3 protein expression levels normalized to $\beta$-actinGAPDH. Data are expressed as mean $\pm \operatorname{SD}(n=3)$. ${ }^{*} p<0.05$, ** $p<0.01$, and ${ }^{* \star *} p<$ 0.001 vs. control; $\# p<0.05$, \#\# $p<0.01$, and \#\#\# $p<0.001$ vs. DOX; $\psi p<0.05$ vs. DOX poly MNPs. 

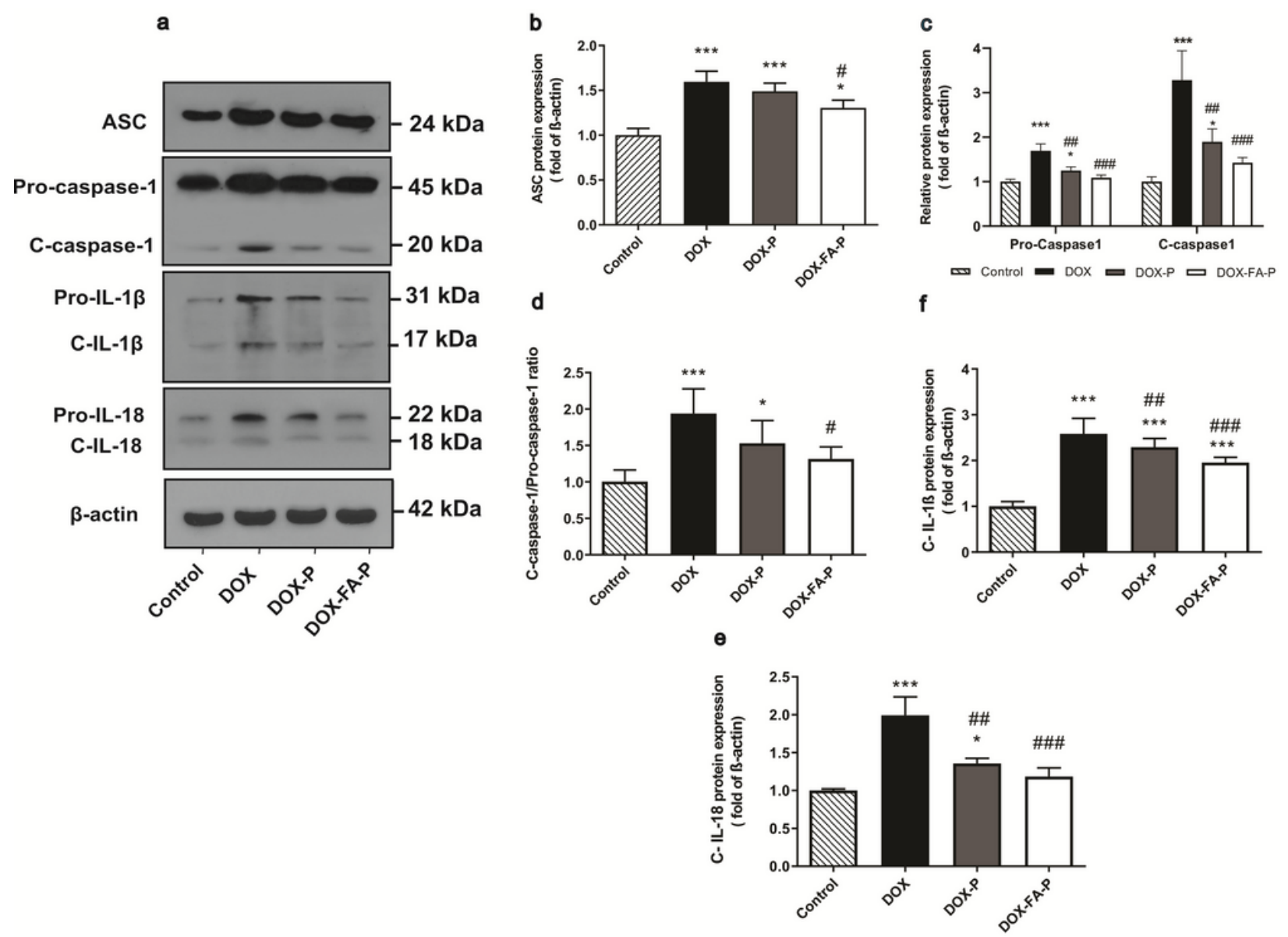

Figure 7

Expression of pyroptosis-related proteins in the cardiac tissues was detected by western blot. (a) Histograms display the density of ASC, (b) pro-caspase-1 and c-caspase-1, (c) the ratio of c-caspase1/pro-caspase-1, (d), c IL 1 $\beta$, and (e), c-lL-18 normalized to $\beta$-actin. Data are expressed as mean \pm SD $(n=3) .{ }^{*} p<0.05$ and ${ }^{\star * \star} p<0.001$ vs. control; $\# p<0.05$, \#\# $p<0.01$, and \#\#\#p<0.001 vs. DOX. 